\title{
Spontaneous bronchobiliary fistula: Case report
}

\author{
Marzia Acquasanta ${ }^{1 *}$, Gaia Spadarella ${ }^{1}$, Enrico Maria Civelli ${ }^{2}$ \\ 1. Postgraduate School in Radiodiagnostics, Università degli Studi di Milano, Milan, Italy \\ 2. Department of Radiology, Istituto Nazionale dei Tumori, Milan, Italy \\ * Correspondence: Marzia Acquasanta, Università degli Studi di Milano, Via Festa del Perdono 7, 20122 Milan, Italy \\ (入marzia.acquasanta@unimi.it)
}

Radiology Case. 2020 Oct; 14(10):10-15 :: DOI: 10.3941/jrcr.v14i10.3743

\begin{abstract}
Bronchobiliary fistula $(\mathrm{BBF})$ is a rare condition that results from the communication between the bile ducts and the bronchial tree. It is characterized by the presence of bile in the sputum as pathognomonic symptom, and it is often associated with suspicious pneumonia. The most common causes include infections (e.g. echinococcosis), hepatobiliary surgery, blunt torso traumas, tumors and percutaneous transhepatic procedures. Opinions about BBF treatment are still controversial as it can be treated by both conservative and surgical procedures, while pharmacological treatments are only rarely used. This case report presents a patient who had been diagnosed with chronic BBF of unknown cause, underwent several ineffective conservative procedures and was at last surgically treated.
\end{abstract}

\section{CASE REPORT}

\section{CASE REPORT}

A 79-year-old man presented to our Institute with a diagnosis of bronchobiliary fistula (BBF) diagnosed one year earlier. When the patient was 21 , he had undergone uncomplicated cholecystectomy. His medical history included a kinking of the upper ureter surgically treated, three-vessel coronary heart disease conservatively treated and an acute myocardial infarction he had suffered 11 years before. He had been a cigar smoker for 50 years.

In the last 4 years he had been complaining about chronic, persistent productive cough with biliptysis (bile in the sputum), so a bronchobiliary fistula was clinically suspected. The computed tomography (CT) revealed an inflammatory pulmonary consolidation in the lateral basal segment of the right lower lobe, with contextual hyperdense components and ipsilateral diaphragmatic pleural calcifications (Fig. 1). A subsequent fistulogram (Fig. 2) demonstrated the presence of a fistulous track connecting the pulmonary consolidation and the intrahepatic biliary tract. During the last year, multiple attempts to treat endoscopically the BBF have been performed, both with biliary and bronchial approach.

Despite all that, the patient came to our Institute still complaining about chronic cough, fever and biliptysis. A new CT scan was performed and revealed the persistence of the BBF (Fig. 3). The thoracic surgeons evaluated the case and decided for the surgical treatment via a lung segmentectomy.

Due to patient's history, preoperative test included a cardiac stress test that showed the evidence of ischemic alterations of the ST-T tract in the precordial derivations V2V6 at the second step, so a three-vessel angioplasty was performed.

After an extensive adhesiolysis, partially extrapleural, and the isolation of the lower-right pulmonary lobe, the surgeons identified the diaphragmatic fistulous track, which size was about $4 \mathrm{~mm}$ in diameter, containing a minimum quantity of fluid collection compatible with material of biliary origin. The 
fistula was sutured, a protective pleural flap was placed and a lateral-basal segmentectomy was performed.

After surgery, a magnetic resonance cholangiography with hepatobiliary-specific contrast media confirmed the absence of a residual fistulous track.

The patient's hospitalization was complicated by a Pseudomonas aeruginosa empyema, so a chest drainage was positioned as initial treatment. The bronchoscopy revealed granulation tissue at the segmental bronchi stumps, with two bronchopleural fistulous tracks, without any evidence of BBF.

Pleural empyema was surgically treated with an open window thoracostomy, allowing a pulmonary adhesiolysis, the resection of the empyematic sacs and the pleural space irrigation with antibiotics.

Now the patient is taking daily home-medications and will be re-evaluated for eventual surgical closure of the thoracic window.

\section{DISCUSSION}

The first case of BBF was reported by Peacock in 1850 in a patient affected by echinococcosis, secondary to the rupture of an hydatid cyst. He described it as an abnormal channel between the biliary tract and the bronchial tree [1].

\section{Etiology \& Pathogenesis:}

Several authors agree that the prevalent causes of BBF include hepatobiliary tumors or hepatic metastases, intrahepatic lithiasis, biliary duct stenosis, cholecystitis, pancreatitis and trauma. Infections resulting in a subdiaphragmatic abscess or necrotizing lung infections can predispose to BBF. It can even be the result of an iatrogenic injury in hepatic surgery or local treatment, such as a radiofrequency ablation $[2,3,4]$. Only a few cases of congenital $\mathrm{BBF}$ are reported [2,5].

Pathogenesis of the non-congenital form is thought to be related to two distinct mechanisms. The first involves biliary tract obstructions (caused by scar tissue, tumors, inflammatory diseases) leading to bile retention proximal to the barrier with consequent formation of a biloma and subsequent formation of an abscess, which gradually erodes the diaphragm. In the second mechanism the abscess formation takes place without biliary tract obstruction and it is most frequently due to an echinococcal hydatic cyst $[3,6]$.

There is only one case of a supposed spontaneous BBF in the literature [7]. When $\mathrm{BBF}$ is the consequence of an iatrogenic surgical injury, it occurs as late complication at the latest within a year, even when surgery is not closely liverlinked $[8,9]$.

In this specific case, the patient had undergone only one surgery in his life, a cholecystectomy for lithiasis without complications almost 60 years earlier. So the hypothesis of a spontaneous BBF is to be considered.

\section{Clinical \& Imaging findings:}

Biliptysis is the pathognomonic symptom which leads to suspect the presence of a BBF. The clinical picture may also include fever and jaundice, dyspnea, irritating cough and pneumonia. Right upper quadrant abdominal pain and chest pain can occur. Anemia, vomiting, hepatic decompensation and portal hypertension are sporadically reported $[2,10,11]$.

To confirm BBF diagnosis, the most sensitive methods are endoscopic retrograde cholangiopancreatography (ERCP), percutaneous transhepatic-cholangiography (PTC) and fistulogram of a biliocutaneus fistula, when possible. Also contrast-enhanced magnetic resonance cholangiography (MRC) can demonstrate the fistulous tract [2,6]. Even if CT scan often fails into the demonstration of the fistulous tract, it can be helpful to detect air into the biliary tree, an underlying hepatic abscess, a pleural effusion or a pulmonary consolidation [12].

Bronchoscopy is not routinely performed, but even when no bile is present in the lavage fluid, the diagnosis of biliary pneumonia and BBF is made on the basis of transbronchial biopsy findings of brown bilious crystals surrounded by neutrophils [13].

\section{Treatment \& Prognosis:}

Opinions about BBF treatment are controversial in the literature.

Although somatostatin and its analogues have been proposed to reduce gastrointestinal secretion, medical therapy alone has not been effective so far in patients with BBF [14].

When possible, non-surgical or conservative interventions should be performed, such as ERCP biliary drainage, percutaneous ultrasound / CT guided drainage of the subdiaphragmatic or intrahepatic abscess, or bronchoscopy guided fistula embolization [2,6], but the success of these methods depends on the status of the inflammatory process [15].

Despite conservative methods are gradually consolidating, surgery remains mostly the only effective option $[2,6,10]$, especially for the treatment of chronic fistulas associated with pulmonary failure or sepsis [15].

In our case, several conservative procedures through biliary or bronchial endoscopy had been ineffective and a surgical approach was chosen at last.

\section{Differential Diagnoses:}

Differential diagnoses include: pleurobiliary fistula and other hepatic or pulmonary masses/thickening.

\section{Pleurobiliary fistula}

Patients with a pleurobiliary fistula may be asymptomatic or could complain about dyspnea and fever.

On imaging, a pleurobiliary fistula can be mistaken for a BBF, but MRC with hepatobiliary contrast media can 
demonstrate the fistulous track confirming that the disease does not exceed the pleural cavity.

CT may demonstrate a peri- or intrahepatic lowattenuation fluid with pleural effusion, in the setting of recent hepatobiliary surgery or trauma. ERCP demonstrates the fistulous track in pleural cavity, but peripheral sites of leakage may not be filled with the retrograde injection [16].

\section{Hepatic lesions, e.g. biloma}

In presence of a subglissonian subdiaphragmatic hepatic lesion, such as biloma, a BBF must be excluded. Patients with biloma are often asymptomatic and become symptomatic when the disease evolves in bile peritonitis.

Biloma has low-attenuation in the right upper quadrant in CT and MRC features similar to gallbladder: bilious fluid demonstrates variable signal intensity on $\mathrm{T} 1 \mathrm{w}$ sequences and high signal intensity on $\mathrm{T} 2 \mathrm{w}$ imaging. MR imaging with hepatobiliary-specific contrast media in the hepatocyte phase demonstrates that the fluid collection is composed of bile and identifies the site of bile leak, excluding the presence of a BBF $[2,17]$.

\section{Pulmonary thickening and atelectasis}

In case of a pulmonary thickening contiguous to the diaphragm, such as a subsegmental or segmental atelectasis, the presence of a BBF should be excluded.

Patients with pulmonary thickening or atelectasis can be asymptomatic or complain about non-productive cough or respiratory failure.

CT with contrast media shows areas of lung consolidation as parenchymal densities of varying thickness parallel to the diaphragm, at the lung bases [18].

In any case, a BBF must be suspected on the basis of clinical findings and imaging helps to reach the diagnosis.

\section{TEACHING POINT}

Even if endoscopic retrograde cholangiopancreatography (ERCP) and percutaneous transhepatic-cholangiography (PTC) are the most preferred procedures to provide the direct photographic evidence of bronchobiliary fistula (BBF), contrast-enhanced magnetic resonance cholangiography (MRC) has the advantage to be a non-invasive technique that not only ensures a definite diagnosis, but also provide anatomical and functional information about biliary tree and flow.

\section{REFERENCES}

1. Peacock TB. Case in which hydatids were expectorated and one of suppuration of hydatid cyst of the liver communicating with the lungs. s.l. : Edinburgh Med J 1850; 74: 33-46. PMID: 30331080 .
2. Liao GQ, Wang H, Zhu GY, Zhu KB, Lv FX, Tai S. Management of acquired bronchobiliary fistula: A systematic literature review of 68 cases published in 30 years. s.l. : World J Gastroenterol 2011 September 7; 17(33): 3842-3849. PMID: 21987628.

3. Yeheyis ET, Tamire AT. Broncho-Biliary Fistula Due to Hydatid Disease: Case Report. s.1. : J Clin Case Rep 7: 1048. doi: 10.4172/2165-7920.10001048. ISSN: 2165-7920.

4. Banerjee N, Rattan A, Priyadarshini P, Kumar S. Posttraumatic bronchobiliary fistula. s.l. : BMJ Case Rep. 2019 Apr 5;12(4). PMID: 30954961.

5. Li TY, Zhang ZB. Congenital bronchobiliary fistula: A case report and review of the literature. s.l. : World J Clin Cases. 2019 Apr 6;7(7):881-890. PMID: 31024960.

6. Crnjac A, Pivec V, Ivanecz A. Thoracobiliary ?stulas: literature review and a case report of ?stula closure with omentum majus. s.l. : Radiol Oncol 2013;47:77-85. PMID: 23450657.

7. Bade BC, Janech MG, Ravenel JG, Stenbit AE. Bronchobiliary Fistula Presenting With Recurrent Pneumonia and Cholelithoptysis. s.l. : Am J Med Sci. 2015 Jul;350(1):723. PMID: 26132519.

8. García MM, María AM, Briz MC. Fístula biliobronquial, una complicación tardía de la cirugía hepática. s.l. : Arch Bronconeumol. 2018;54:285-286. ISSN: 03002896.

9. Odufalu FD, Zubairu J, Silverman W. Bronchobiliary fistula: a rare complication after pancreaticoduodenectomy. s.l. : BMJ Case Rep. 2018 Sep 4;2018. pii: bcr-2017-221895. PMID: 30181397.

10. Shim JR, Han SS, Park HM, Lee EC, Park SJ, Park JW. Two cases of bronchobiliary fistula: Case report. s.l. : Ann Hepatobiliary Pancreat Surg 2018;22:169-172. PMID: 29896580.

11. Tran T, Hampel H, Qureshi WA, et al. Successful endoscopic management of bronchobiliary ?stula due to radiofrequency ablation. s.1. : Dig Dis Sci 2007;52:3178-80. PMID: 17638080.

12. D'Altorio RA, McAllister JD, Sestric GB, Cichon PJ. Hepatopulmonary fistula: treatment with biliary metallic endoprosthesis. s.1. : Am J Gastroenterol 1992;87:784-6. PMID: 1590321.

13. Matsumoto T, Otsuka K, Kaihara S, Tomii K. Biliary Pneumonia due to the Presence of a Bronchobiliary Fistula. s.1. : Intern Med. 2017;56(11):1451-1452. PMID: 28566617.

14. Ong M, Moozar K, Cohen LB. Octreotide in bronchobiliary fistula management. s.l. : Ann Thorac Surg 2004; 78: 1512-1513; author reply 1513. PMID: 15464539.

15. Kontoravdis N, Panagiotopoulos N, Lawrence D. The challenging management of hepatopulmonary fistulas. s.l. : J Thorac Dis. 2014 Sep;6(9):1336-9. PMID: 25276379. 
16. Melamud K, LeBedis CA, Anderson SW, Soto JA. Biliary imaging: multimodality approach to imaging of biliary injuries and their complications. s.l. : Radiographics. 2014 MayJun;34(3):613-23. PMID: 24819784.
17. Haaga JR, Boll D. CT and MRI of the whole body. s.l. : Mosby. (2009). ISBN:0323053750.

18. JC., Reed. Chest Radiology. s.l. : (2017). ISBN: 9780323498319.

\section{FIGURES}
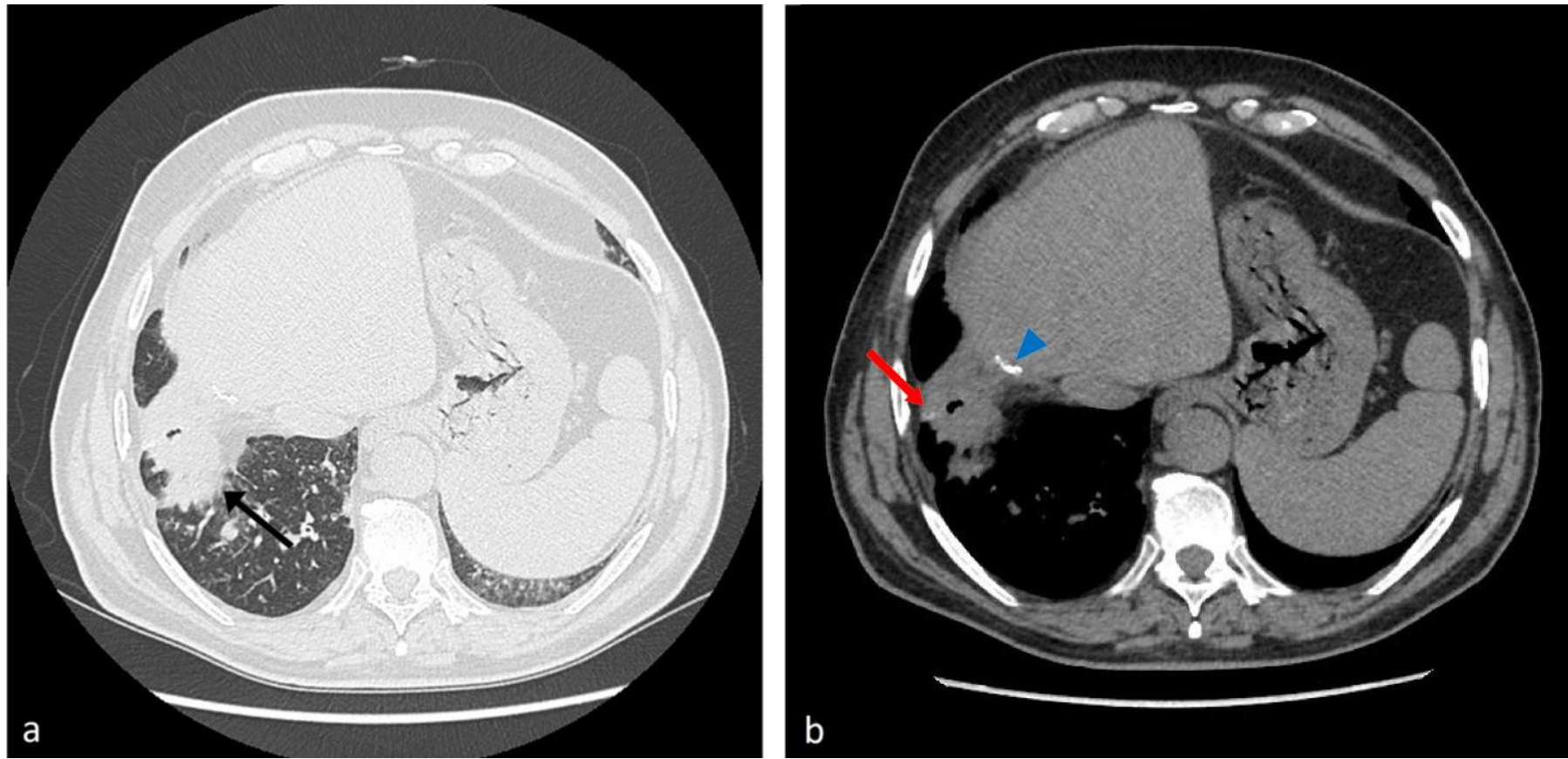

Figure 1: 79-year-old man with a bronchobiliary fistula.

a. FINDINGS: Axial non-contrast enhanced CT of the lung in lung window demonstrating an inflammatory pulmonary consolidation in the lateral basal segment of the right lower lobe (black arrow).

TECHNIQUE: Helical CT (LightSpeed VCT), 125mAs, $120 \mathrm{kV}, 0,75 \mathrm{~mm}$ slice thickness.

b. FINDINGS: Axial non-contrast enhanced CT scan of the lung in mediastinal window demonstrating hyperdense components (red arrow) in the right pulmonary consolidation and ipsilateral diaphragmatic pleural calcifications (blue arrowhead).

TECHNIQUE: Helical CT (LightSpeed VCT), 125mAs, $120 \mathrm{kV}, 0,75 \mathrm{~mm}$ slice thickness.

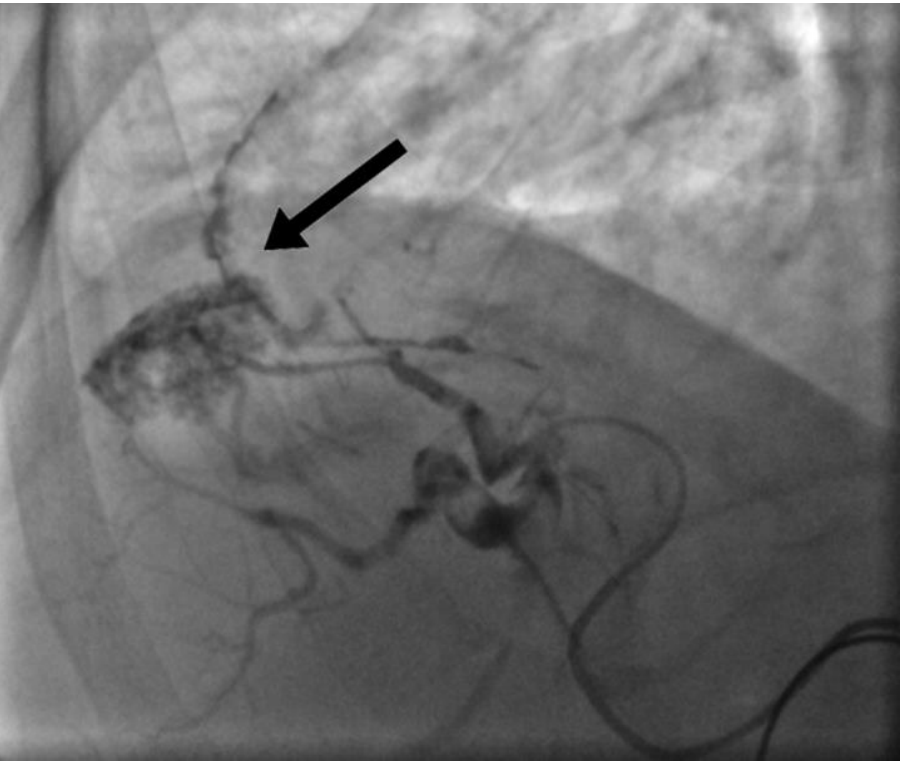

Figure 2 (left): 79-year-old man with a bronchobiliary fistula. FINDINGS: Fistulogram shows the presence of a fistulous track (black arrow) between the pulmonary bronchus and the bile duct for the hepatic VII segment.

TECHNIQUE: Air-Kerma 1844 mGy. Endoscopic retrograde cholangiopancreatography, Iomeprol $350 \mathrm{mgI} / \mathrm{mL}(20 \mathrm{ml})$. Total timing: 20 minutes. Identified is the right hepatic duct, contrast media is injected into the anterior branch and the bronchobiliary fistula is visualized. 

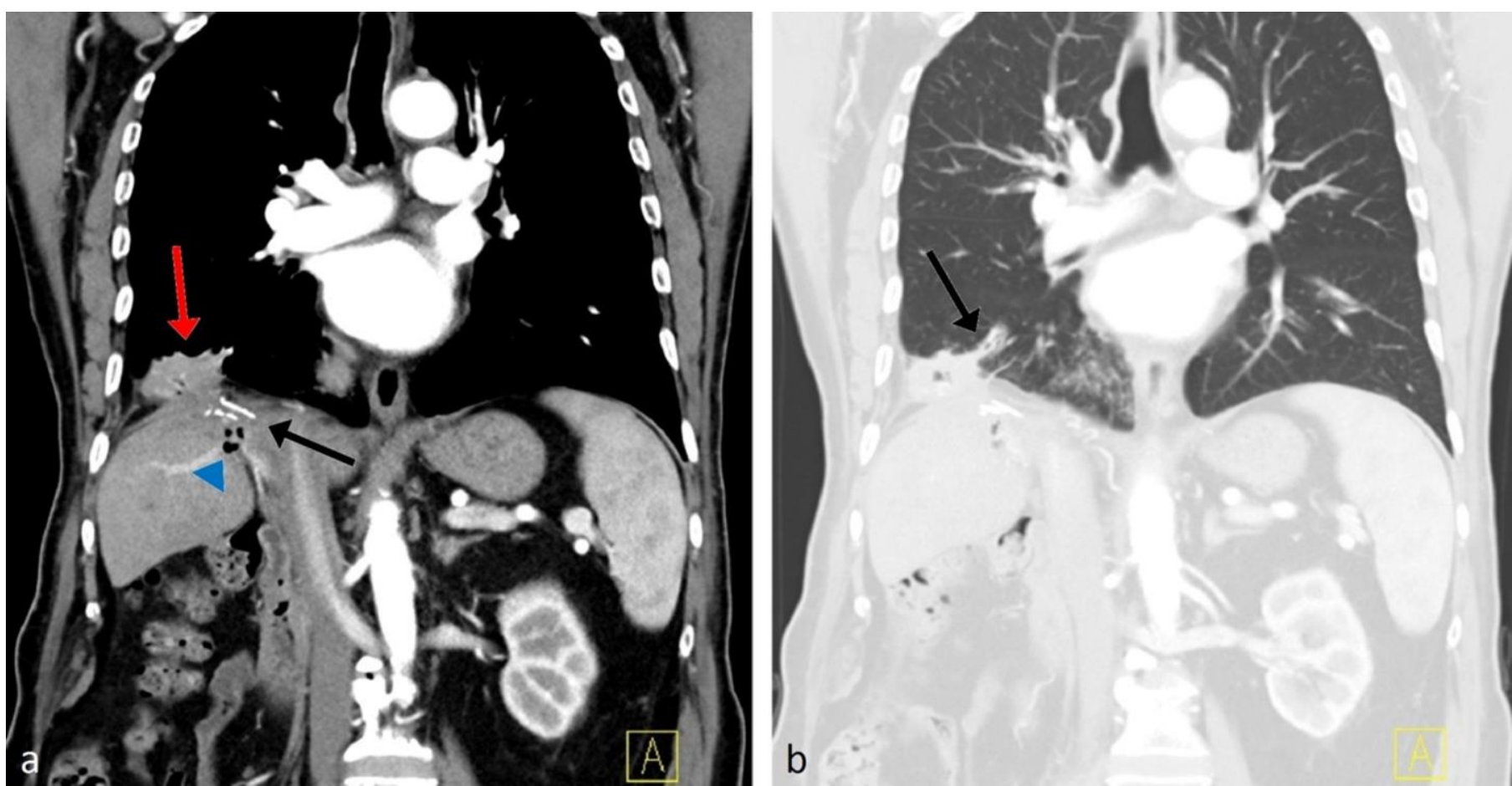

Figure 3: 79-year-old man with a bronchobiliary fistula.

a. Coronal CT reconstruction with mediastinal window (arterial phase).

b. Coronal CT reconstruction with lung-window.

FINDINGS: Contrast enhanced coronal CT scan of the lung confirms the inflammatory pulmonary consolidation (red arrow) and shows the sequela of previous interventions (diaphragmatic pleural calcifications) to conservatively resolve the bronchobiliary fistula (black arrows); aerobilia is present (blue arrowhead).

TECHNIQUE: Helical CT (SOMATOM Definition Flash), 125 mAs, 120 kV, 0,75 mm slice thickness, Iopamidol, $370 \mathrm{mgI} / \mathrm{mL}$ $(90 \mathrm{ml})$.

\section{Etiology}

- Congenital [2]

- Infectious (first of all echinococcosis) $[1,2,3]$

- $\quad$ Liver surgery and treatments $[2,3,8]$

- Gallbladder surgical procedures $[2,3,8]$

- Traumatic events [2,3]

- Tumors $[2,3]$

\section{Treatment}

- Pharmacological treatment: somatostatin and its analogues [14]

- Non-surgical or conservative interventions via ERCP or PTC $[2,6]$

- $\quad$ Surgery $[2,6,10,15]$

\section{Findings on imaging}

- Fistulogram shows the presence of a fistulous track between the pulmonary bronchus and the bile duct $[2,6]$

- Also, endoscopic retrograde cholangiopancreatography (ERCP), percutaneous transhepatic-cholangiography (PTC), contrast-enhanced magnetic resonance cholangiography (MRC) show the presence of the fistulous track [2,6]

- CT scan demonstrates the presence of air into the biliary tree, hepatic abscess, pleural effusion, pulmonary consolidation. Rarely it demonstrates the fistulous tract [12]

Table 1: Summary table for bronchobiliary fistula. 


\begin{tabular}{|c|c|c|c|c|}
\hline & Clinical findings & $\overline{C T}$ & MRI & $\begin{array}{l}\text { ERCP/PTC and } \\
\text { fistulogram }\end{array}$ \\
\hline $\begin{array}{l}\text { Bronchobiliary } \\
\text { fistula }\end{array}$ & $\begin{array}{l}\text { Biliptysis, fever and } \\
\text { jaundice, dyspnea, } \\
\text { irritating cough, and } \\
\text { pneumonia. }[2,10,11]\end{array}$ & $\begin{array}{l}\text { Air into the biliary tree, } \\
\text { hepatic abscess, pleural } \\
\text { effusion, pulmonary } \\
\text { consolidation. } \\
\text { Rarely it demonstrates } \\
\text { the fistulous tract. [12] }\end{array}$ & $\begin{array}{l}\text { MRC demonstrated } \\
\text { the fistulous track. } \\
\text { The hepatocyte phase } \\
\text { demonstrates contrast } \\
\text { material leakage with } \\
\text { the bronchial tree. } \\
{[2,6]}\end{array}$ & $\begin{array}{l}\text { ERCP, PTC and } \\
\text { fistulogram can } \\
\text { demonstrate the } \\
\text { presence of the } \\
\text { fistulous track. }[2,6]\end{array}$ \\
\hline $\begin{array}{l}\text { Pleurobiliary fistula } \\
{[16]}\end{array}$ & $\begin{array}{l}\text { Non-specific symptoms } \\
\text { and sings; dyspnea and } \\
\text { fever can occur. }\end{array}$ & $\begin{array}{l}\text { Peri- or intrahepatic low- } \\
\text { attenuation fluid with } \\
\text { pleural effusion in the } \\
\text { setting of recent } \\
\text { hepatobiliary surgery or } \\
\text { trauma. }\end{array}$ & $\begin{array}{l}\text { MRC demonstrated } \\
\text { the fistulous track. } \\
\text { The hepatocyte phase } \\
\text { demonstrates contrast } \\
\text { material leakage into } \\
\text { the pleural cavity. }\end{array}$ & $\begin{array}{l}\text { ERCP demonstrates } \\
\text { fistulous track in } \\
\text { pleural cavity, but } \\
\text { peripheral sites of } \\
\text { leakage may not be } \\
\text { filled with the } \\
\text { retrograde injection. }\end{array}$ \\
\hline $\begin{array}{l}\text { Hepatic lesions, e.g. } \\
\text { biloma [17] }\end{array}$ & $\begin{array}{l}\text { Asymptomatic. } \\
\text { Symptomatic bile } \\
\text { peritonitis. }\end{array}$ & $\begin{array}{l}\text { Bilious fluid low- } \\
\text { attenuation is usually } \\
\text { seen in the right upper } \\
\text { quadrant. }\end{array}$ & $\begin{array}{l}\text { Bilious fluid } \\
\text { demonstrates variable } \\
\text { signal intensity on } \\
\text { T1w sequences and } \\
\text { high signal intensity } \\
\text { on T2w imaging. } \\
\text { The hepatocyte phase } \\
\text { demonstrates that the } \\
\text { fluid collection is } \\
\text { composed of bile and } \\
\text { identifies the site of } \\
\text { bile leak. }\end{array}$ & \\
\hline $\begin{array}{l}\text { Pulmonary } \\
\text { thickening and } \\
\text { atelectasis [18] }\end{array}$ & $\begin{array}{l}\text { Asymptomatic. } \\
\text { Non-productive cough. } \\
\text { Respiratory failure. }\end{array}$ & $\begin{array}{l}\text { Subsegmental and } \\
\text { segmental atelectasis is } \\
\text { seen as parenchymal } \\
\text { densities of varying } \\
\text { thickness usually parallel } \\
\text { to the diaphragm, most } \\
\text { commonly at the lung } \\
\text { bases. }\end{array}$ & & \\
\hline
\end{tabular}

Table 2: Differential diagnosis table for bronchobiliary fistula.

\section{ABBREVIATIONS}

BBF: bronchobiliary fistula

CT: computed tomography

ERCP: endoscopic retrograde cholangiopancreatography

MRC: magnetic resonance cholangiography

PTC: percutaneous transhepatic-cholangiography

\section{KEYWORDS}

Bronchobiliary fistula; biliobrochial fistula; fistulogram; lung; biliary tree; inflammatory pulmonary consolidation

\section{Online access}

This publication is online available at: www.radiologycases.com/index.php/radiologycases/article/view/3743

\section{Peer discussion}

Discuss this manuscript in our protected discussion forum at: www.radiolopolis.com/forums/JRCR

\section{Interactivity}

This publication is available as an interactive article with scroll, window/level, magnify and more features. Available online at www.RadiologyCases.com

Published by EduRad

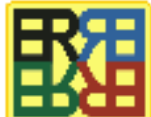

www.EduRad.org 